gant rate. Now men trained in the knowledge of how plants live and grow and behave have some basis on which they can suggest ways of managing forests which will not only yield all the timber that is needed at the present time, but which will enable these forests to continue to yield such supplies for an indefinite period of years. Forest management is not unknown in other countries. We simply have trained no men in this country to have any idea what forest management means.

And then we have the immense subject of diseases of plants, and that is a study which seems to have attracted the greatest attention at the present day. The division of vegetable pathology at the Department of Agriculture at Washington is receiving a vast deal more attention than the division of forestry, and yet I doubt very much whether its money value to the people is any greater. The money value of the study of both these subjects to the American people, and particularly to the farmers of the country, is almost beyond calculation. We hardly realize what this money value is. We are so used to losing a certain percentage of our farm crops by diseases that we really pay no attention to it. If our animals, our flocks and herds, should be decimated as often as the crops are, we should hear such a bue and cry as would bring immediate attention on all hands to it. I suppose there is no one of you, who has given the subject a moment's thought, but will agree with me that the loss from rust on the wheat crop for the present year, stated in the very lowest possible terms, could not fall below one per cent. How much money does that mean on six hundred odd million bushels of wheat? It means several million more than has been laid out in the study of plants in all the centuries. It means a great many hundreds of thousands of dollars more than we shall lay out the next century for the study of plants; and yet we are learning and can learn how not only to check but how absolutely to prevent such diseases as this. I do not say that this particular one can be absolutely checked at the present time, but we know ways in which it can be reduced to a minimum, even at present. The same thing might be said in regard to such diseases as those of the smut in corn and oats. Very careful estimates of certain years have shown us that as much as ten per cent sometimes of an oat crop is damaged by that one disease alone. That might mean a good many millions of dollars on that one crop. So that a study of these plant diseases is by no means either fruitless or valueless.

But you say, "Why not let anybody who is concerned with these matters study them?" Chiefly because it is not possible for any man who does not know something of the life history of the parasite which causes a disease to go about checking or curing it. He may guess at some remedy, and he may, by a lucky guess, hit upon the right remedy. He may think of some process that possibly will turn out the right one, but he is not nearly so apt to think about the right process or to hit upon the right experiment as the man who has been properly trained for this kind of work. That sort of training means time to study, and time to work, and money support while the work is being carried on.

I might $d$ well at very much greater length on these various topics; but enongh has been said, I hope, to give you some idea of what modern botany is and what the modern botanist is. It will at least give you a truer idea than you would have if you considered him merely as the man who goes out and gathers some plants, useful as this may be, or the man who tears apart some flowers to find out what the names of the flowers are. Rather, I would have you think of the botanists of the country as those men who are studying means of discovering, checking, and curing the plant diseases; men who are studying how plants grow, and how they may be helped in their growth and not harmed. They are men who are studying what is the rational basis for our modes of culture; and it is to these men the agriculturist must turn, with the hope that their experiments will lead him in the future, as they have in the past, to more rational modes of cultivation, and to better knowledge of the organisms, the very intricate organisms in spite of their simplicity, with which he has constantly to deal.

\section{NOTES ON A DESTRUCTIVE FOREST TREE SCOLYTID.}

BY ANDREW D. HOPKINS.

THE family of beetles known as Scolytidæcontains in this country, so far as known, something over 160 species. They are small, cylindrical, brown or black beetles. The largest one of the family, Dendroctonus terebrans, is thirty-two hundredths of an inch long, while the smallest, Cripturgus atomus, is but four hundredths of an inch long. With a few exceptions, beetles belonging to this family breed in the bark of wood of different forest and fruit trees. Each species usually has a preference for certain kinds of trees. Those feeding on the bark are called bark beetles, while those entering the wood are termed timber beetles. The bark beetles breed in and feed upon the inner bark of trees or logs, and when fully developed emerge through the bark, leaving it pierced with small round holes. The timber beetles enter directly through the bark, making their "pin-hole" tunnels in all directions through the wood; their eggs are deposited in these tunnels, and when the young are fully developed they emerge from the original entrance made by the parent beetle.

It has been claimed that Scolytids never attack healthy, living trees. We acknowledge that as a rule the different species of this family have a preference for unhealthy trees or those which have been broken by storm or felled by the axe, but in this Dendroctonus frontalis we certainly have an exception to the rule. From the abundant evidence I have obtained during extended and careful investigation, I am convinced that the death of large and small, vigorous trees of five species of pine and of the black spruce was caused primarily by the attack of this insect; in fact, this species seems to have a preference for the green bark on the living pine and spruce which they invade.

As Entomologist of this Station, I have conducted some investigations regarding the ravages of this beetle, and, since May 2 of this year, have travelled about 340 miles through some of the principal regions of the State, where the pine and spruce are most common. The species of pine observed were the White Pine (Pinus alba), the Yellow Pine ( $P$. echinata), the Pitch Pine ( $P$. rigida), the Table Mountain Pine ( $P$. pungens), and the common Scrub Pine ( $P$. inops). The Black Spruce (Picea Mariana) is also a common and valuable tree on some 500,000 acres of the higher mountains and table-lands of this State.

Trees varying from five inches in diameter to the largest, finest specimens of the five species of pine mentioned, and of the Black Spruce, were found dying in different sections from a cause which it was my duty to investigate. A large number of the dead, dying, and green trees wore felled and examined. Every part of the trees from the roots near the surface to the terminal twigs and leaves was carefully 
searched for possible causes of their unhealthy condition. The trees in the best condition to examine were those on which the leaves were yet green, but from their general appearance indicated that they had been attacked by the characteristic trouble which was shown in a few yellow leaves at the tops. The roots of such trees were found in a perfectly healthy condition for some distance beneath the surface; the bark on the trunks from a distance of from five to fifteen feet from the base was green, full of sap, and apparently healthy; the leaves were almost free from insect attack and disease, in no case was there sufficient attack of this nature to. indicate even a slight injury; the bark, however, at a point about two-thirds up from the base of the tree, was found in every case to be infested by Dendroctonus frontalis in sufficient numbers to kill all the bark for some distance above that point, and in this bark fully-developed beetles and pupæ were found on May 5, thus indicating that the eggs must have been deposited in the bark the previous summer or fall. All of the characteristic dead and dying Pine and Spruce trees examined showed abundant evidence that they had been invaded while yet green by this bark beetle.

It would seem that the turpentine escaping into the burrows made by the beetles in the green bark would render the conditions unfavorable for the progress of their work. They have, however, the power of removing it from their burrows, and they manipulate the sticky resinous substance with seemingly as much ease and in a like manner as the craw fish does the clay it piles up around its burrow. Often a half teaspoonful of the turpentine will be found massed about the entrance to the burrows made by the beetle. They push the turpentine out through a hole kept open in the pitchy, adhesive mass. I have observed them backing out from the entrance, shoving behind them a quantity of the turpentine, and at the same time they would be completely enveloped in it.

Trees invaded by these beetles the previous fall may remain green until spring when they are usually attacked by the large Dendroctonus terebrans, Hylurgops glabratus, and Tomicus calligraphus, the two former at the base of the tree, the latter in the green bark above. They are in turn followed by numerous other species of bark and timber beetles until the invaded trees may be, as I have found, the hosts of at least twenty-five species of scolytids coming like reinforcements to the aid of $D$. frontalis to make doubly sure the death of the invaded trees. Later on, these scolytids are followed by insects belonging to other families until a dead or dying tree may be the host of hundreds of species and millions of examples, breeding in and feeding upon every part of the tree from the base to the terminal twigs, rendering it worthless for lumber within a year after it dies.

Thus it will be seen that Dendroctonus frontalis may be the primary cause of not only the death of the trees but of their rapid decay.

West Va. Agricultural Experiment Station, Morgantown, West Va., July 20

\section{LETTERS TO THE EDITOR.}

*** Correspondents are requested to be as brief as possible. The writer's name is in all cases required as proof of good faith.

On request in advance, one hundred copies of the number containing his communication will be furnished free to any correspondent.

The editor will be glad to publish any queries consonant with the character of the journal.

\section{Auroral Display.}

ON Saturday evening, July 16 , there was visible, from this locality, in the northern heavens, the most brilliant auroral display which I have witnessed since the year 1859. Besides the usual exhibition of streamers of various hues, dancing along the northern arch like great hanging curtains, there was one most unique feature which I never saw or heard of before. A little after 10 o'clock, when the great brilliance of red and pink streams seemed to be dying out, and the northern heavens assuming a pale uniform hue, there appeared directly overhead a well-defined, nebulous arch, spanning the entire vault of heaven from east to west. At first a companion suggested that it was the Milky Way; but a few seconds' observation detected the Milky Way, running nearly at right angles with the arch - the two resembling each other somewhat in width and general appearance, except that the arch was more clearly defined and uniform in shape and outline than the other. In about fifteen minutes it began to fade away and disappear, the eastern portion disappearing first. In a short time there was only a bright strip near the western horizon, which much resembled the tail of a comet; but it, too, soon disappeared, and there were then no traces of the arch to be seen.

However, in a few minutes it began to reappear, and soon shone out bright and clear as before, - the arch being five to six degrees in width, - the eastern extremity at the horizon being a little south of east, and the other extremity being a little north of west. as if the whole had been drawn by a radius of a circle whose centre was a little east of the north pole. In ten or fifteen minutes this arch also disappeared as before.

Between the arch and the upper extremities of the gay streamers in the north there were several degrees of space lighted up by stars, and without any apparent connection between them. The band or arch seemed wider at the zenith than on either horizonprobably the effect of the greater distance of the horizon points from the position of the observer. The night air was quite cool, and I retired before midnight; and I have not learned whether or not the arch again reappeared.

T. A. BEREMAN

Mount Pleasant, Ia., July 20.

\section{Magnetic Storm, Aurora, and Sun-Spots.}

A MAGNETIC storm raged here from 10.30 A.M to 4.30 P.M., central time, on Saturday, July 16, 1892. An electro-magnetic wave reached the general telegraph office of the C. B. \& Q. R. R. at 10.30 A.M., making it difficult to operate, especially with the quadruplex. The duration of the electric disturbance was six hours; but the impulses came with varying intensity. The energy always appeared as a wave, beat, or oscillation; and when fully developed in the wires, seemed to set up a counter electro-motive force in opposition to the batteries. The fact that electro-magnetic energy traverses space in the form of waves, coincides with the now classical experiments of Hertz, who projected these waves not only through space, but brick walls. Perhaps a law like this will be discovered - All modes of energy alternate.

It is doubtful if a constant pressure exists in nature. In some instances, telegrams have been sent by means of nature's electricity - without batteries. This is merely a prophecy of that time coming when men will appropriate electricity when they want it, as they do light and heat.

An aurora appeared at 9.40 P.M., and consisted of many pearlcolored columns, at times tinged with red, occupying more than $100^{\circ}$ in azimuth, and all converging near Polaris.

A.t 9.45 an apparition unusual in auroral displays was seen. This was a streamer of nearly white light, that, starting in a sharp point almost on the horizon, in the north-west, shot with great velocity north of Arcturus, passed over Corona Borealis, which constellation it equalled in diameter, crossed Hercules and Cerberus, and; passing over Aitair, descended almost to Mars in the south-east, terminating also in a fine point.

This majestic sword moved bodily $10^{\circ}$ to the south, and, after shivering and pulsating throughout its length three times, vanished, after existing fourteen minutes. The whole aurora lasted forty minutes. On July 9, a large cluster of spots, with two smaller groups and one larger isolated spot, were seen on the sun. All the larger spots had bridges, and on the 12 th and 13th the tongues across the large one began to curve, which curvature rapidly increased on the 14 th and 15 th. On the 16 th, these jets were arranged nearly in a circle, or had assumed 